ARTICLE

\title{
Tectonic and climatic drivers of Asian monsoon evolution
}

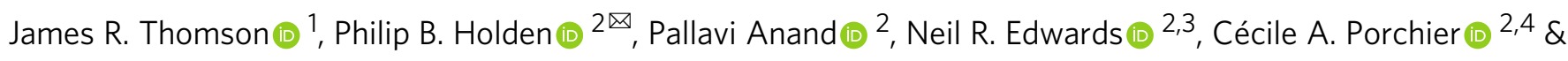
Nigel B. W. Harris (1) ${ }^{2}$

Asian Monsoon rainfall supports the livelihood of billions of people, yet the relative importance of different drivers remains an issue of great debate. Here, we present 30 million-year model-based reconstructions of Indian summer monsoon and South East Asian monsoon rainfall at millennial resolution. We show that precession is the dominant direct driver of orbital variability, although variability on obliquity timescales is driven through the ice sheets. Orographic development dominated the evolution of the South East Asian monsoon, but Indian summer monsoon evolution involved a complex mix of contributions from orography (39\%), precession (25\%), atmospheric $\mathrm{CO}_{2}(21 \%)$, ice-sheet state $(5 \%)$ and ocean gateways (5\%). Prior to $15 \mathrm{Ma}$, the Indian summer monsoon was broadly stable, albeit with substantial orbital variability. From $15 \mathrm{Ma}$ to $5 \mathrm{Ma}$, strengthening was driven by a combination of orography and glaciation, while closure of the Panama gateway provided the prerequisite for the modern Indian summer monsoon state through a strengthened Atlantic meridional overturning circulation.

\footnotetext{
${ }^{1}$ Safety in Engineering Ltd, South Lanarkshire, UK. ${ }^{2}$ School of Environment, Earth \& Ecosystem Sciences, The Open University, Milton Keynes, UK.

${ }^{3}$ Cambridge Centre for Energy, Environment and Natural Resource Governance, University of Cambridge, Cambridge, UK. ${ }^{4}$ Present address: Department of Geography, University College London, London, UK.凶email: Philip.Holden@open.ac.uk
} 
P roxy reconstructions and modelling studies have shown multiple drivers of Asian monsoon variability: orbital forcing, atmospheric carbon dioxide $\left(\mathrm{CO}_{2}\right)$, global ice volume, Himalayan-Tibetan Plateau (HTP) uplift, tectonicallyinduced changes to major ocean gateways, and Intertropical Convergence Zone (ITCZ) movement, via atmospheric circulation changes and Atlantic Meridional Overturning Circulation (AMOC) teleconnections. However, a comprehensive and systematic assessment of all these drivers together has been lacking but is necessary to quantify their relative roles and the interactions between them. A recent modelling study ${ }^{2}$ based on snapshot HadCM3 simulations at 3 million-year (Myr) intervals, for the past $150 \mathrm{Myr}$, suggested that tectonic uplift dominated the evolution of the East Asian Monsoon, one of the subsystems of the Asian Monsoon ${ }^{2}$. However, this approach does not adequately address the relative effects of different drivers against one another, or the interactions between multiple drivers, noting that these drivers have been shown to impact monsoon dynamics over a range of timescales ${ }^{3}$.

On the timescales of interest, transient simulations of sufficient length to be useful are computationally intractable; even the most efficient atmosphere-ocean GCMs would require thousands of years of computing. We overcome this problem by using emulation, a widely used approach in climate science that generates fast approximations to simulations by deriving statistical relationships between model inputs and outputs. We build emulators of monsoon rainfall simulated by the intermediate complexity Earth system model PLASIM-GENIE ${ }^{4}$ in response to changing boundary conditions for the last $30 \mathrm{Myr}$. We consider the Asian Monsoon subsystems (ISM and SEAM) separately as they are known to be influenced by distinctly different wind systems and moisture sources ${ }^{1,5}$. This fact has incited considerable debate about their coupling on orbital and millennial scales ${ }^{6-9}$. We use these emulators to perform a global sensitivity analysis ${ }^{10}$, enabling us to disentangle the roles of all the principal drivers on the ISM and SEAM, and then to generate time-series of rainfall reconstructions at high (1000-year) resolution by providing the proxy-based boundary conditions and timing of major tectonic changes as inputs to the emulators (Figs. 1 and 2). By simulating three alternative paleogeographies, we capture the first-order effects of the two main ocean gateways, but not the full effects of the retreat of the Tethys and Paratethys oceans ${ }^{11-13}$, still ongoing in the Miocene ${ }^{14}$, with increasing continentality displacing pressure systems and triggering changes in monsoon strength.

In this work, we show that while long-term SEAM evolution is dominated by orographic development, which drives $93 \%$ of the modelled SEAM variance since $30 \mathrm{Ma}$, controls on the strength of the ISM are more complex, and include an important role for atmospheric $\mathrm{CO}_{2}$ (driving $21 \%$ of the modelled ISM variance) and significant roles for ice-sheets and ocean gateways. The orbital variability of both systems is dominated by precession, although variability over obliquity time scales is driven through ice sheets.

\section{Results and discussion}

Sensitivity to climate drivers. Summer rainfall dominates the modern Indian and South East Asian monsoons as winter monsoons are dry. We emulate annual precipitation, which we regard as the variable most representative of precipitation and runoff proxies, and apply the terms ISM and SEAM, noting that the area covered in the latter is commonly referred to as East Asian Summer Monsoon (EASM). The modelled areas of the ISM and SEAM are shown in Fig. 3a.

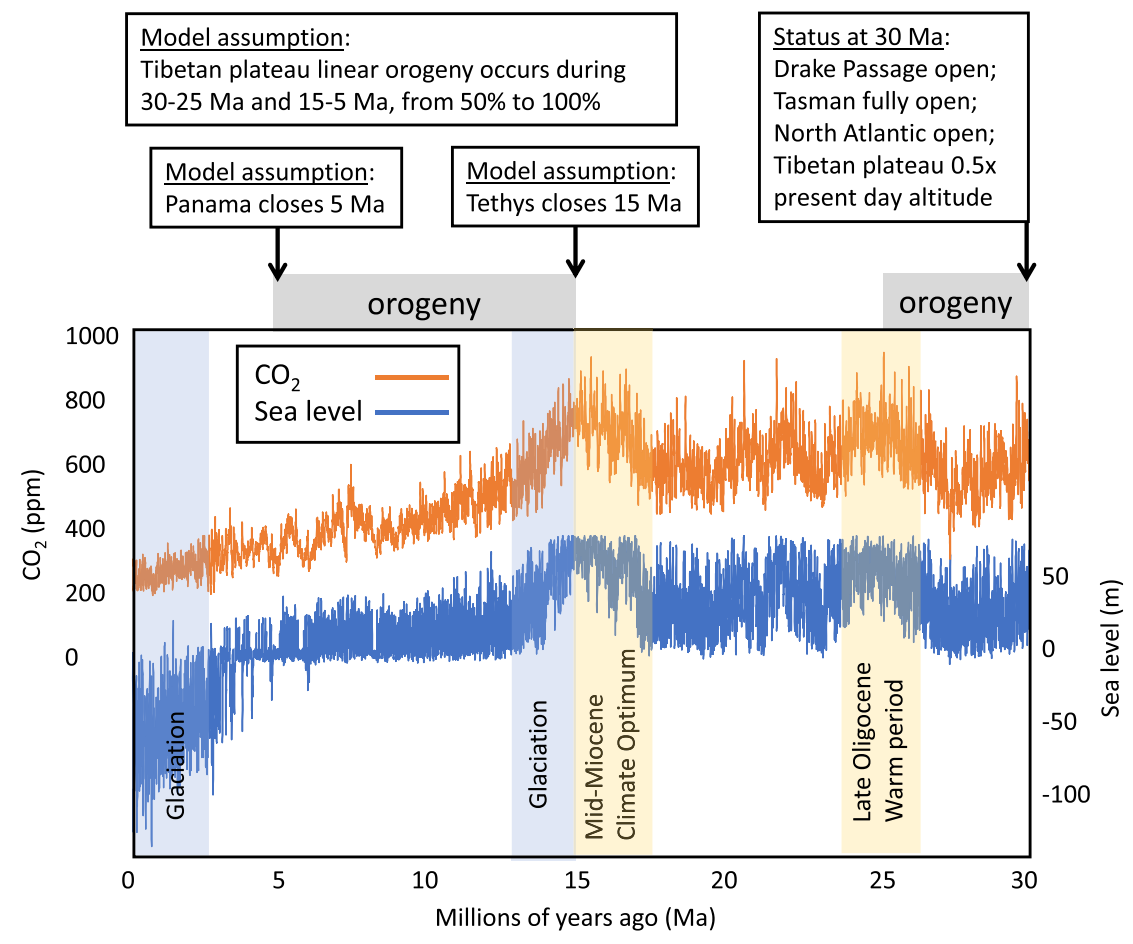

Fig. 1 Major tectonic and climatic boundary conditions considered in the model for the past $\mathbf{3 0}$ Myr. Changing boundary condition modelled are Himalayan-Tibetan Plateau (HTP) orogeny $15,28,34,41-44$ (represented by a globally uniform scaling of orogeny), Tethys gateway closure 27, Panama gateway closure ${ }^{61-64}$, orbital parameters ${ }^{56}$, atmospheric $\mathrm{CO}_{2} 47,48$ and the ice-sheet state derived from sea-level reconstructions ${ }^{48}$. Model assumptions include linear orogeny lifting between 30-25 Ma and 15-5 Ma from 50 to $100 \%$ of present day, final Tethys closure at $15 \mathrm{Ma}$ and Panama closure at $5 \mathrm{Ma}$. The model assumes that Drake passage, Tasman and North Atlantic gateways were open at $30 \mathrm{Ma}$. See Supplementary Materials for discussion of data and references. 

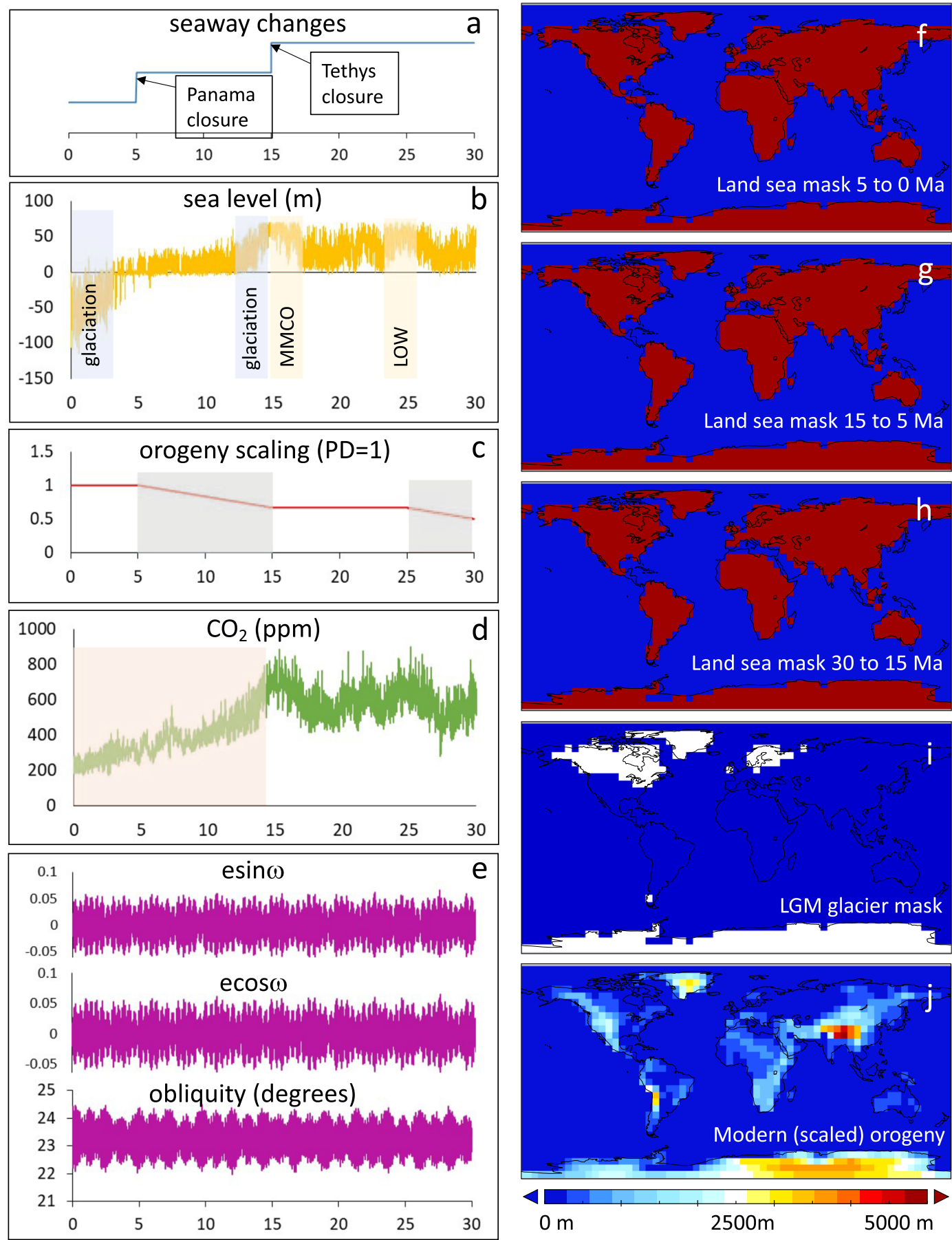

e
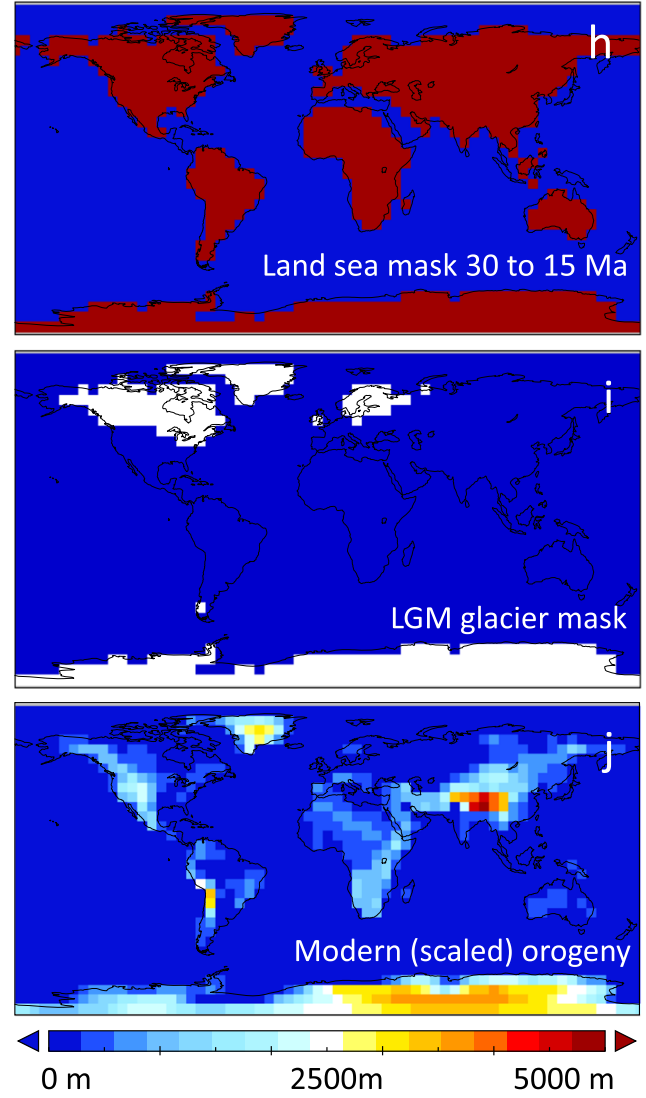

Age (Ma)

Fig. 2 Boundary conditions used in this study. Left panels are the time-series forcing, also used to derive priors for the total effect calulations (Supplementary Table 1), showing the assumed timing of (a) seaway land-sea mask changes, (b) sea-level ${ }^{48}$ (MMCO Mid-Miocene Climate Optimum, LOW Late Oligocene Warming), (c) orogeny scaling (PD present day), (d) atmospheric $\mathrm{CO}_{2}^{47,48}$ and (e) orbital forcing 56 (e eccentricity, $\omega$ longitude of the perihelion at the vernal equinox). Right-hand panels show the (f) $5 \mathrm{Ma}$ to present, (g) 15-5 Ma, and (h) 30-15 Ma land-sea masks used in the study, (i) the Last Glacial Maximum (LGM) ice sheets ${ }^{74}$ and (j) the modern orogeny.

Our global sensitivity analysis considers changes in tectonic, atmospheric $\mathrm{CO}_{2}$, sea level (from which we infer the ice-sheet state) and orbital forcing since $30 \mathrm{Ma}$ (Fig. 1; Table 1). The sensitivity analysis is derived from large ensembles of emulations, drawing inputs randomly from prior distributions that are derived from the forcing time series (Fig. 2 and Supplementary Table 1). We calculate the "total effect" of each input, which is the expectation of the variance that would remain if all other inputs were known, and thus quantifies the sensitivity of the system to that input in isolation.

For SEAM rainfall, orogeny explains $93 \%$ of the variance over the last $30 \mathrm{Myr}$. Orogeny particularly dominated the rainfall variability during the Oligocene and Miocene $e^{1,15}$ but eccentricity, obliquity, $\mathrm{CO}_{2}$, sea level (ice-sheet state) and precession each contribute comparably to rainfall variability during the PlioPleistocene (when the model assumes attainment of present-day 
a

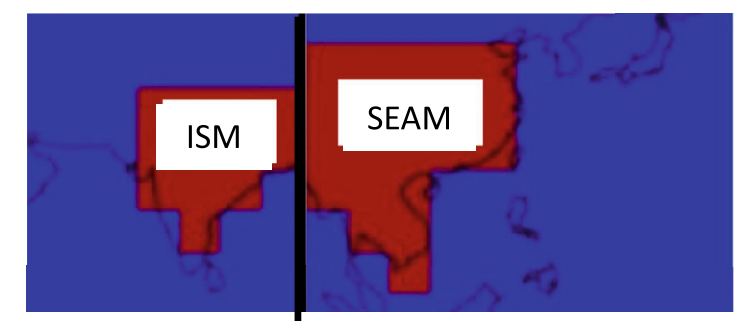

SEAM
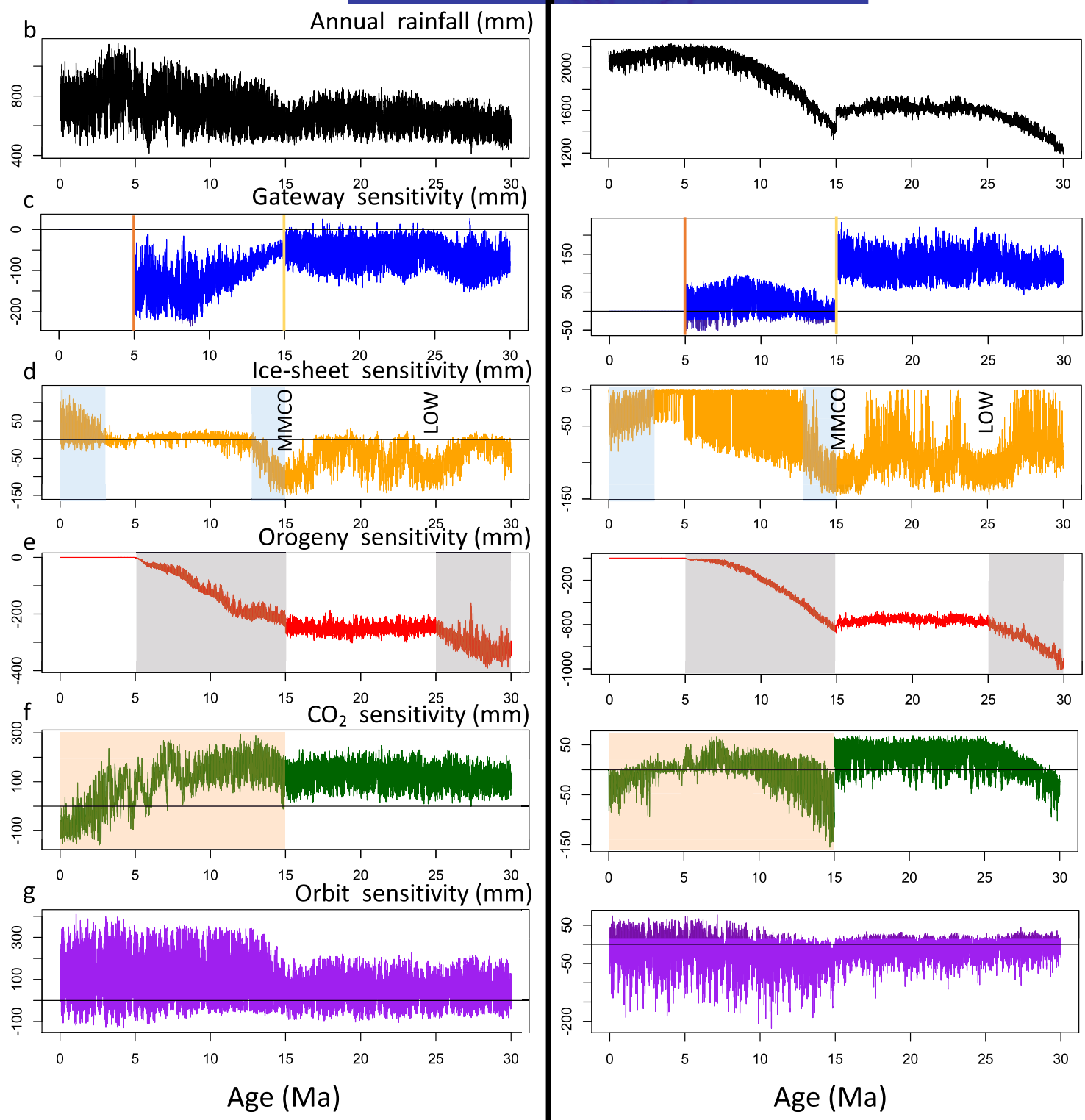

Fig. 3 Monsoon rainfall and sensitivities since $30 \mathrm{Ma}$, showing the difference between the baseline rainfall and rainfall assuming the input is fixed at its preindustrial value. a Modelled areas for Indian Summer Monsoon (ISM, left panel) and South East Asian Monsoon (SEAM, right panel). b Emulated rainfall. c Gateway sensitivity. Vertical lines are closing of Tethys gateway (yellow) and closing of Panama gateway (orange) Vertical labels are the MidMiocene Climate Optimum (MMCO) and Late Oligocene Warming (LOW). d Sea-level/ice volume sensitivity. Light blue shading are times of glaciation. e Orography sensitivity. Grey shaded areas are periods of tectonic uplift. $\mathbf{f} \mathrm{CO}_{2}$ sensitivity. Light red shading shows period of $\mathrm{CO}_{2}$ drawdown. $\mathbf{g}$ Orbital sensitivity. Note the different $y$-axis scales used for the different forcings and for the two monsoon systems.

orography) (Table 1). Our Pleistocene results are in concert with terrestrial and marine records $s^{5,8,16,17}$ suggesting multiple drivers (precession, obliquity, ice sheet and $\mathrm{CO}_{2}$ ) impacting SEAM rainfall variability.

For ISM variability, precession is the dominant driver over the last $30 \mathrm{Myr}$, except during the Miocene, when orogeny and $\mathrm{CO}_{2}$ are of comparable importance to (and amplify) precession, reflecting significant changes in these boundary conditions during this period (Table 1). The dominance of precession on Pleistocene ISM variability has been demonstrated in cave $^{18}$ and marine ${ }^{7}$ records. The greatest rainfall variance is apparent in the Pliocene, largely driven by the global $\mathrm{CO}_{2}$ decrease (Table 1 ). Considering the entire $30 \mathrm{Myr}$ interval, all of the modelled boundary conditions except obliquity played a significant role, with orogeny (39\%), precession (25\%) and $\mathrm{CO}_{2}(21 \%)$ exerting the strongest controls on ISM rainfall. 
Table 1 Total effects on annual rainfall for each epoch (upper) ISM and (lower) SEAM.

\begin{tabular}{|c|c|c|c|c|c|c|c|c|c|}
\hline & Holo-cene & Pleisto-cene & Pliocene & Miocene & $\begin{array}{l}\text { Late Miocene } \\
\text { 15.97-5.333 Ma }\end{array}$ & $\begin{array}{l}\text { Early Miocene } \\
23.03-15.97 \mathrm{Ma}\end{array}$ & Oligo-cene & $\begin{array}{l}30 \mathrm{Ma} \text { to } \\
\text { pre-industrial }\end{array}$ & $\begin{array}{l}30 \mathrm{Ma} \text { to pre- } \\
\text { industrial } \% \text { of total }\end{array}$ \\
\hline \multicolumn{10}{|l|}{ ISM } \\
\hline $\mathrm{CO}_{2}$ & $13 \pm 2$ & $44 \pm 6$ & $63 \pm 11$ & $55 \pm 13$ & $73 \pm 4$ & $14 \pm 1$ & $16 \pm 1$ & $71 \pm 5$ & $21 \%$ \\
\hline Sea level & $9 \pm 1$ & $16 \pm 1$ & $14 \pm 1$ & $31 \pm 3$ & $28 \pm 3$ & $29 \pm 1$ & $24 \pm 1$ & $35 \pm 3$ & $5 \%$ \\
\hline Precession & $127 \pm 4$ & $106 \pm 5$ & $123 \pm 4$ & $91 \pm 5$ & $91 \pm 8$ & $59 \pm 3$ & $55 \pm 5$ & $77 \pm 5$ & $25 \%$ \\
\hline Obliquity & $11 \pm 2$ & $9 \pm 1$ & $12 \pm 1$ & $20 \pm 1$ & $18 \pm 1$ & $17 \pm 1$ & $13 \pm 1$ & $17 \pm 1$ & $1 \%$ \\
\hline Eccentricity & $43 \pm 1$ & $36 \pm 1$ & $44 \pm 0.4$ & $32 \pm 2$ & $33 \pm 3$ & $25 \pm 1$ & $25 \pm 1$ & $30 \pm 2$ & $4 \%$ \\
\hline Orogeny & 0 & 0 & $2 \pm 0.1$ & $65 \pm 4$ & $66 \pm 4$ & 0 & $20 \pm 1$ & $97 \pm 3$ & $39 \%$ \\
\hline Gateways & - & - & - & - & - & - & - & $35 \pm 1$ & $5 \%$ \\
\hline Total & 135 & 121 & 146 & 134 & 142 & 74 & 71 & 155 & $100 \%$ \\
\hline \multicolumn{10}{|l|}{ SEAM } \\
\hline $\mathrm{CO}_{2}$ & $2 \pm 0.1$ & $20 \pm 2$ & $11 \pm 0.4$ & $23 \pm 1$ & $24 \pm 1$ & $6 \pm 1$ & $11 \pm 0.3$ & $31 \pm 1$ & $1 \%$ \\
\hline Sea level & $9 \pm 0.3$ & $16 \pm 0.2$ & $13 \pm 1$ & $31 \pm 1$ & $33 \pm 1$ & $24 \pm 1$ & $24 \pm 0.2$ & $35 \pm 1$ & $1 \%$ \\
\hline Precession & $39 \pm 3$ & $36 \pm 3$ & $38 \pm 2$ & $31 \pm 1$ & $30 \pm 1$ & $17 \pm 1$ & $15 \pm 0.4$ & $28 \pm 1$ & $1 \%$ \\
\hline Obliquity & $14 \pm 1$ & $13 \pm 1$ & $10 \pm 0.4$ & $10 \pm 1$ & $11 \pm 1$ & $9 \pm 1$ & $8 \pm 1$ & $10 \pm 1$ & $<1 \%$ \\
\hline Eccentricity & $19 \pm 4$ & $18 \pm 2$ & $19 \pm 1$ & $20 \pm 1$ & $19 \pm 1$ & $14 \pm 0.3$ & $12 \pm 1$ & $17 \pm 1$ & $<1 \%$ \\
\hline Orogeny & 0 & 0 & $5 \pm 1$ & $184 \pm 1$ & $181 \pm 1$ & 0 & $109 \pm 2$ & $298 \pm 1$ & $93 \%$ \\
\hline Gateways & - & - & - & - & - & - & - & $55 \pm 1$ & $3 \%$ \\
\hline Total & 46 & 49 & 47 & 192 & 189 & 34 & 114 & 309 & $100 \%$ \\
\hline \multicolumn{10}{|c|}{$\begin{array}{l}\text { Total effects quantify the variance in precipitation that is attributable to the respective driver (methods). Total effects (aside from percentages) are provided as their square roots to aid comparison by } \\
\text { converting this variance measure to units of } \mathrm{mm} / \text { day. Mean and } 1 \text {-sigma uncertainties are provided for each by repeating each calculation ten times with different (stochastically derived) emulators. } \\
\text { Significant drivers in each epoch are highlighted; bold face text highlights drivers that contribute at least } 20 \% \text { variance to that epoch while italicised text highlights drivers that contribute } 5-20 \% \text { to the } \\
\text { variance in that epoch. The gateways comprise the effects of Tethys and Panama closure. Over } 30 \mathrm{Myr} \text { (RH column), SEAM rainfall has been dominated by orogeny, whereas ISM rainfall has been driven } \\
\text { mostly by a combination of orogeny, precession and } \mathrm{CO}_{2} \text {, with significant effects from sea level (ice volume) and ocean gateways. Note that while the Total Effects are dominantly a function of the prior } \\
\text { of the parameter under question, they also depend upon the priors of the other variables through parameter interactions (methods). For this reason, the total effects in the Miocene cannot be derived } \\
\text { from the values in the late and early Miocene, and may take values outside of their range. }\end{array}$} \\
\hline
\end{tabular}

To supplement the emulated sensitivity analysis we also performed six snapshot simulations with PLASIM-GENIE in order to better understand the underlying model dynamics. These simulations represent the preindustrial state and five sensitivities, having orography reduced by $50 \%, \mathrm{CO}_{2}$ doubled to $560 \mathrm{ppm}$, Last Glacial Maximum (LGM) ice sheets added, Panama gateway opened and precession in the opposing phase. The simulation outputs are provided in Supplementary Figs. 2-7, and used to inform the discussion that follows.

Our finding that orogeny dominates emulated SEAM rainfall, while multiple factors impact ISM rainfall is new but not surprising, because the ISM and SEAM are known to be distinct physical systems ${ }^{19,20}$, and relatively higher sensitivity of SEAM to orogeny compared to ISM has been shown in proxy reconstructions ${ }^{21}$. This differing behaviour is supported by the single-forcing PLASIMGENIE simulations (Supplementary Figs. 2-7). A 50\% reduction in orogeny compared to pre-industrial drives a substantial weakening of the June-July-August (JJA) Hadley circulation at the longitude of the SEAM $107^{\circ} \mathrm{E}$ (Supplementary Fig. 4) and Walker circulation (Supplementary Fig. 7), and is associated with a reduction in JJA and annual rainfall (Supplementary Figs. 2 and 17) over the entire SEAM region. However, although the other four drivers affect the spatial distribution of SEAM rainfall, these changes are not associated with a substantial reorganisation of the Hadley circulation, and rainfall change averaged over the SEAM area has been dominated by orogeny. In contrast, significant changes in JJA Hadley circulation at $79^{\circ} \mathrm{E}$ (the approximate longitude of the ISM) are driven by each of the five forcings considered. Reduced orogeny, LGM ice sheets and opened Panama gateway all drive a weakened JJA Hadley circulation at $79^{\circ} \mathrm{E}$ and reduced ISM rainfall. LGM ice sheet ${ }^{22}$ and open Panama gateway ${ }^{23,24}$ are associated with a southerly shift of the ITCZ. In the case of the opened Panama gateway, the shift in the ITCZ is driven by Atlantic-Pacific salinity redistribution ${ }^{23,24}$, collapse of the $\mathrm{AMOC}^{25}$ (Supplementary Fig. 5) and redistribution of interhemispheric ocean heat content (Supplementary Fig. 6). Conversely, doubled $\mathrm{CO}_{2}$ drives continental warming ${ }^{26}$, which strengthens the Hadley circulation at $79^{\circ} \mathrm{E}$ and drives increased ISM rainfall. Similarly, a phase reversal in precession drives warming in the northern summer, a northerly shift of the JJA ITCZ, strengthened Hadley circulation and increased ISM rainfall.
Monsoon rainfall changes since $30 \mathrm{Ma}$. Monsoon rainfall is influenced both by direct effects such as physical changes to atmospheric flow driven by orogeny, $\mathrm{CO}_{2}$ and Earth's orbital configuration and by indirect teleconnections, via atmospheric and oceanic circulation. These drivers influence the atmospheric circulation by both the meridional shifts in the ITCZ via Hadley Cells (affecting rainfall) as discussed in the previous section and zonal shifts of Walker Cells (affecting wind direction particularly in SE $\mathrm{Asia}^{2}$ ) or any other factors impacting them, for example, ocean circulation changes such as AMOC strength and Tethys Indian Saline Water (TISW) ${ }^{27}$. We discuss the impact of monsoon drivers, and their influences, on rainfall changes (Fig. 3b) and, using sensitivity analysis, isolate the contribution of each driver in turn (Fig. 3c-g) over the $30 \mathrm{Myr}$ study interval by subtracting the results of a repeat emulation, fixing the parameter at preindustrial conditions.

For the period $30 \mathrm{Ma}$ to $15 \mathrm{Ma}$, Fig. 3b shows ISM rainfall increased $(\sim 100 \mathrm{~mm})$ due to the elevated orography, with lesser (temporary) effects due to reduced ice volume during the Late Oligocene Warming (LOW) and Mid-Miocene Climate Optimum (MMCO) (see Supplementary Fig. 1), and continuous oscillations due to orbital forcing. For the same period, SEAM rainfall increased significantly, mainly driven by increasing orography during 30-25 Ma, and with lesser effects of climate variability during LOW and MMCO. Orbital forcing had a much smaller effect on SEAM than ISM rainfall throughout the entire $30 \mathrm{Ma}$ interval. The growth of the high altitude central and southern HTP (in both area and elevation) is likely to have occurred prior to $15 \mathrm{Ma}^{28}$ and so uplift tectonics impacts significantly on the SEAM during this period.

The period after $15 \mathrm{Ma}$ is more complex with renewed orogeny, gateway closures, and ice-sheet (sea level) changes each having effects on both monsoon systems. Final Tethys closure at $15 \mathrm{Ma}$ caused rapid, pronounced rainfall reduction in SEAM, with negligible effect on ISM rainfall (Fig. 3b, c). The step change in SEAM rainfall at $15 \mathrm{Ma}$, coincident with Tethys closure, seen in the $\mathrm{CO}_{2}$ sensitivity (Fig. $3 \mathrm{f}$ ) suggests an interaction between these two forcings i.e. when $\mathrm{CO}_{2}$ is reduced to $280 \mathrm{ppm}$, emulated rainfall decreases when Tethys is closed, but increases when Tethys is open. We performed additional sensitivity simulations 
to explore JJA rainfall for some of these interactions, using the same values as the single-parameter sensitivities, but combining them into eight combinations of Tethys open/closed, $\mathrm{CO}_{2}$ $560 \mathrm{ppm} / 280 \mathrm{ppm}$ and global orogeny scaling 1.0/0.5 (Supplementary Fig. 8). Tethys closure drives a simulated reduction in SEAM rainfall in all four scenarios, albeit with a substantial difference in magnitude and distribution, illustrating strong interaction. At $50 \%$ orogeny, reducing $\mathrm{CO}_{2}$ from $560 \mathrm{ppm}$ to $280 \mathrm{ppm}$ reduces simulated annual rainfall from $1320 \mathrm{~mm}$ to $1300 \mathrm{~mm}$ when Tethys is closed. In contrast, when Tethys is open, reducing $\mathrm{CO}_{2}$ from $560 \mathrm{ppm}$ to $280 \mathrm{ppm}$ increases annual rainfall from $1216 \mathrm{~mm}$ to $1242 \mathrm{~mm}$. It is worth noting that these interactions are even more complex for the ISM, as Tethys closure drives rainfall change of uncertain sign, depending on the background state (Supplementary Fig. 8).

After Tethys closure, increasing orogeny (Fig. 3e) during the period $15 \mathrm{Ma}$ to $5 \mathrm{Ma}$ caused an increase in monsoon rainfall which has been inferred to be due to lower summer Asiatic atmospheric pressures ${ }^{1}$ and strengthened Hadley-Walker circulation over East $\mathrm{Asia}^{2}$, consistent with PLASIM-GENIE simulations (Supplementary Figs. 4 and 7). Furthermore, $\mathrm{CO}_{2}$ drawdown began after $15 \mathrm{Ma}$ and continued more-or-less until the Industrial Revolution (Fig. 1), driven by HTP weathering, and led to global cooling ${ }^{29}$. These three effects-atmospheric disturbance caused by orogeny, $\mathrm{CO}_{2}$ drawdown, and increasing ice volumeproduced competing effects in terms of monsoon rainfall. Both SEAM and ISM rainfall show increasing sensitivity to orbital forcing from about $15 \mathrm{Ma}$, peaking by around $12 \mathrm{Ma}$, associated with times of increasing Antarctic glaciation and orogeny forcing (Fig. 2).

During the period $14 \mathrm{Ma}$ to $10 \mathrm{Ma}$, SEAM rainfall shows orbital variability synchronous with increases in ice volume and obliquity minima (Supplementary Fig. 10), in agreement with proxy data ${ }^{3,30}$. This strong obliquity signal on SEAM rainfall is likely due to the indirect effect of high-latitude teleconnection with northern hemisphere ice sheets, as the total effect analysis reveals a weaker relationship with obliquity than sea level (Table 1). SEAM rainfall peaked at c. $7 \mathrm{Ma}$, as orogeny approached its present-day elevation.

Panama closure at $5 \mathrm{Ma}$ had minimal effect on SEAM rainfall but caused a dramatic increase of $\sim 100 \mathrm{~mm} /$ year on ISM rainfall (Fig. 3c). We infer this ISM rainfall increase to be driven by indirect teleconnections arising from constriction of the Panama gateway, which led to increased AMOC ${ }^{31}$ (Supplementary Fig. 5), redistribution of interhemispheric ocean heat content (Supplementary Fig. 6) and consequent northward movement of the ITCZ ${ }^{32,33}$. Falling $\mathrm{CO}_{2}$ after $3 \mathrm{Ma}$ drove a reduction in ISM rainfall (Fig. 3f), despite a competing increase driven by Pleistocene glaciation. The ice-sheet sensitivity simulation reveals a weakened JJA Hadley circulation (Supplementary Fig. 4) that drives reduced JJA precipitation (Supplementary Fig. 2), but this is offset in the annual average by an increase in DJF precipitation due to strengthened winds blowing onto the subcontinent from the Bay of Bengal. The relative contributions of these seasonal changes are not robust under parametric uncertainty (Supplementary Fig. 13) and should be treated with caution.

It is instructive to compare these long-term changes with a review of proxy reconstruction evidence ${ }^{34}$ that concluded that the SEAM intensified between 25 and $20 \mathrm{Ma}$, putatively in response to northern HTP uplift. Further intensification has been associated with northeastern and eastern HTP uplift from 15 to $10 \mathrm{Ma}^{35,36}$, possibly masked by the competing effects of $\mathrm{CO}_{2}$ drawdown, cooling and increasing glaciation ${ }^{34}$. Our emulations are broadly consistent with these inferences, although orographic forcing dominates in our results, and clear net strengthening of SEAM rainfall is emulated in response. Proxy evidence further indicates transient increases in SEAM intensity at around 16-14 $\mathrm{Ma}$ and 4.2-2.8 $\mathrm{Ma}^{34}$. Similar events are seen in the ISM emulator at around these times (14-13 Ma and 4-3 Ma), but are absent in the SEAM emulator, which is dominated by orography in this period. During the Pleistocene, proxies indicate SEAM weakening, but with increased orbital variability ${ }^{34}$. This weakening is apparent (though modest) in the SEAM emulation, driven by a combination of ice-sheet and $\mathrm{CO}_{2}$ forcing. Although increased variability is evident in our emulated records, this increase occurs earlier, over the period $15-13 \mathrm{Ma}$, possibly associated with the final HTP uplift, unrelated to Pleistocene boundary conditions. Orbital timescale monsoon variability has been evidenced in proxy records throughout the last $30 \mathrm{Ma}$ and earlier ${ }^{37-39}$, suggestive of both low-latitude precessional forcing and highlatitude obliquity forcing via ice sheets, and consistent with our emulators. A direct comparison of orbital variability between our regional-scale emulators and individual, locally-influenced proxy records would be extremely challenging 40 , but possible in principle if a sufficient density of proxy reconstruction records could be assembled.

Summary. In summary, we conclude that the responses of the ISM and the SEAM to evolving forcing conditions are complex, driven by composite interactions between forcings. This complexity is especially evident in the ISM rainfall evolution, which is driven by competing climatic ice-sheet and $\mathrm{CO}_{2}$ effects during the Miocene and Pliocene. These results need to be validated in the proxy-based ISM precipitation records from the Miocene through to the Pliocene at orbital resolution. Multiple records capturing the spatial and temporal variability in response to these climatic factors will strengthen our understanding of the precipitation response. We recommend that the two Asian Monsoon subsystems, SEAM and ISM, need to be considered as entirely distinct systems, and furthermore, the role of boundary conditions should be considered collectively in future studies. The ISM is especially sensitive to $\mathrm{CO}_{2}$ change, and our results suggest that the scale of future changes in monsoon rainfall strength can be expected to be comparable to the scale of historical variations since at least the start of the Holocene, and probably comparable to that triggered by all forcing factors over the last 30 million years

\section{Methods}

Boundary conditions. The boundary condition input data are summarised in Fig. 2.

The timing and extent of Himalayan-Tibetan Plateau (HTP) orogeny have been subject to sometimes conflicting assessments ${ }^{15,28,34,41-46}$. For modelling purposes, we have assumed that HTP orogeny occurred at a constant rate between 30-25 Ma and 15-5 Ma, doubling in height between $30 \mathrm{Ma}$ and the present day. We also assumed that Himalayan-Tibetan orogeny was uniform within the entire HTP region, whereas the HTP expanded in area, as well as growing in height, at different times. These simplifying, or even simplistic, assumptions are justified on the basis that (a) the exact history of Tibetan orogeny remains uncertain, and (b) the objective in the present work is to evaluate the relative importance of all the potential factors, including orogeny, which could affect monsoon strength.

PLASIM-GENIE is a low-resolution model ( $~ 5$ degrees), and as such the HTP is represented by only $5 \times 2$ grid cells (Fig. 2). A uniform uplift assumption is therefore most appropriate. We chose to apply this as a simple global scaling of present-day orography. As appropriate for a low-resolution model, we emulate rainfall changes on large spatial scales, averaged over the entire ISM and SEAM regions (Fig. 3a). More detailed spatial diagnostics, and assumptions of spatially variable orogeny growth, would require significantly higher model resolution, beyond what is tractable with current computing power, even with the benefit of emulation.

Ice-core $\mathrm{CO}_{2}$ data are used when available ${ }^{47}$, but prior to $800 \mathrm{ka} \mathrm{CO}_{2} \mathrm{data}^{48}$ reconstructed from a zonally averaged energy balance climate model bidirectionally coupled to a one-dimensional ice sheet model were used; these capture ice-albedo and surface-height-temperature feedbacks. These data vary from others ${ }^{49}$ that use a continuous alkenone-based $\mathrm{CO}_{2}$ record from a single marine site, but which show a problematic decoupling of global climate from $\mathrm{CO}_{2}$. The reconstructed $\mathrm{CO}_{2}$ data $^{48}$ are broadly consistent with average global temperature trends, whereas the 
alkenone-based data ${ }^{49}$ are inconsistent with the Mid-Miocene Climate Optimum $(\mathrm{MMCO})^{50-52}$. A possible partial explanation of this apparent anomaly has been proposed $^{53}$ suggesting caution in the interpretation of alkenone-based records at low $\mathrm{CO}_{2}$ levels. $\mathrm{A} \mathrm{CO}_{2}$ peak during the MMCO has been ascribed to outgassing arising from Columbia River flood basalt, which dates between 16.7 and $15.9 \mathrm{Ma}^{54}$.

Sea level changes based on calculated global ice volumes were used ${ }^{48}$. Major increases in glaciation occurred, coincident with large falls in eustatic sea level, at $\sim 34 \mathrm{Ma}$ (onset of Antarctic glaciation coincident with opening of the Drake passage and formation of the Antarctic Circumpolar Current (ACC)), 14 Ma (coincident with Greenland and West Antarctic glaciation), and $\sim 3 \mathrm{Ma}$ (the onset of Pleistocene glaciation $)^{55}$

Orbital forcing data were taken from astronomical modelling ${ }^{56}$. Changes in vegetation types affect climate due to albedo and evapotranspiration feedbacks, but quantitative data over $30 \mathrm{Ma}$ are not available. Although the self-shading parameter, which controls the maximum simulated vegetation density, was varied in the simulation ensemble, for emulation purposes vegetation was limited by selfshading to the tuned value ${ }^{57}$ of $11.5 \mathrm{~m}^{2} \mathrm{kgC}^{-1}$.

Modelling used three gateway states: Panama and Tethys gateways both open (pre-15 Ma), Panama gateway only open (15-5 Ma), and modern world (post-5 Ma). Before $30 \mathrm{Ma}$, the Tarim basin had become dry ${ }^{58}$, the Drake passage was open $^{23}$, Antarctic Circumpolar Circulation (ACC) was established ${ }^{59}$, and North Atlantic Deep Water (NADW) was established (perhaps aided by GreenlandScotland ridge subsidence $\left.{ }^{60}\right)$. Land-sea masks for the three modelled gateway states are illustrated in Fig. 2. The depths of the opened gateways are both assumed to be $\sim 1000 \mathrm{~m}$.

Final Tethys closure, modelled at $15 \mathrm{Ma}^{27}$, has been proposed as a driver of AMOC by reversing flow through the Gibraltar Strait. Tethys closure also led to global cooling by stopping the formation and circulation of Tethyan Indian Saline Water (TISW), which previously transported heat from the northern Indian Ocean to the Southern Ocean ${ }^{27}$.

We assume Panama closure at $5 \mathrm{Ma}$, although evidence is inconclusive ${ }^{61-64}$ Unmodelled gateway changes include the Fram Strait opening to deep water at 18-14 Ma ${ }^{65}$, Iceland formation at $\sim 17 \mathrm{Ma}^{60}$, temporary closure of the Straits of Gibraltar 6-5.3 $\mathrm{Ma}^{66}$, and Bering Strait opening (shallow) at $\sim 5 \mathrm{Ma}^{67}$. Constraint of Indonesian Through Flow (ITF or the Eastern Tethys) between Indian and Pacific Oceans began $\sim 25 \mathrm{Ma}$, and this may have caused long-term El Niño leading ultimately to the Pliocene Warm Period, but the Makassar Strait remained deep enough that ITF was not cut off even during Pleistocene glaciation ${ }^{68-71}$, so ITF constraint is not modelled here.

Supplementary Fig. 1 summarises the calculation methodology.

PLASIM-GENIE is a coupling of the intermediate-complexity spectral atmosphere model PLASIM to the Grid-Enabled Integrated Earth system model GENIE $^{4}$. We applied the model at a spectral T21 atmospheric resolution (5.625 degrees) with 10 vertical layers, and a matching ocean grid with 16 logarithmically spaced depth levels, using the optimised parameter set ${ }^{72}$. We generate quasiequilibrium 2000-year simulations in geared ocean-atmosphere mode ${ }^{73}$, in which PLASIM-GENIE alternates between conventional coupling (for 1 year) and a fixedatmosphere mode (for 9 years).

Ensemble design. Two 200-member ensembles were performed, each using a different maximin Latin hypercube design on eight varied parameters, being the ocean gateway configuration (present day, Panama open, both Tethys and Panama open), ice sheet state (present day, Last Glacial Maximum ${ }^{74}$, only East Antarctic Ice Sheet, no ice sheets), the vegetation self-shading parameter ${ }^{57}$ (from 0.5 to 20 $\mathrm{m}^{2} \mathrm{kgC}^{-1}$ ), global orography scaling (from 0 to 1 in the first ensemble, from 0.5 to 1 in the second ensemble), $\mathrm{CO}_{2}$ concentration (varied with logarithmic spacing from 160 to $1500 \mathrm{ppm}$ ) and the three orbital parameters. The sampling strategy for the orbital variables (eccentricity, the longitude of the perihelion at the vernal equinox and obliquity) followed Araya-Melo ${ }^{75}$, uniformly sampling in the range -0.07 to 0.07 (first ensemble) and -0.05 to 0.05 (second ensemble) and in the range $21^{\circ}$ to $26^{\circ}$ (first ensemble) $22^{\circ}$ to $25^{\circ}$ (second ensemble).

Emulators were constructed as Gaussian processes $(\mathrm{GP})^{76}$, using the DiceKriging R package ${ }^{77}$. GPs are highly flexible non-parametric regression models, widely used in the climate modelling community, which have greater modelling power than linear models. Best-fit emulators were determined under leave-one-out cross-validation, varying the covariance function, mean function, nugget value option, number of iterations, and convergence tolerance. $\mathrm{R}^{2}$ was used as a measure of goodness-of-fit. Tests showed that using esin $\omega$ and $\operatorname{ecos} \omega$ inputs yielded better performance than e and $\omega$. Two outlying simulations were eliminated due to numerical instabilities in PLASIM-GENIE. The final emulators exhibit $\mathrm{R}^{2}$ values of $80 \%$ for India and $96 \%$ for SE Asia under cross-validation.

Total effects ${ }^{10}$ were calculated to assess quantitatively the relative importance of each parameter during each geological epoch. The total effect of an input parameter is the expectation of the output variance that would remain if all other parameters were known. For both India and SE Asia, two hundred ensembles, each with two hundred members, were performed for each parameter in each epoch. Each ensemble fixes the other parameters at some random value (drawn from their respective priors), while the tested parameter is varied across the ensemble (drawn from its prior). Different priors were derived for each epoch, considering the appropriate variability in the forcing data (Fig. 2 and Supplementary Table 1).
Normally distributed priors were used for all parameters except for mvelp and oro (uniform distributions) and world (which is selected as appropriate for each epoch). The mean variance of the 200 ensembles (for each parameter and epoch) is the total effect of that parameter in that epoch. The total effects for the whole period $30 \mathrm{Ma}$ to preindustrial were also assessed, with the parameter world ascribed a value according to the relative duration of each world state over $30 \mathrm{Ma}$.

Time-series emulations were constructed in 1000-years steps over the last 30 Mya, using the forcing data time series in Fig. 2.

PLASIM-GENIE validation. The climate of PLASIM-GENIE has been validated against modern observations $s^{4,73}$ and against model inter-comparisons of the midHolocene, the Last Glacial Maximum, the Last Interglacial transient and the midPliocene warm period ${ }^{72}$. These analyses, which all used the 'optimised' parameter set used to build the emulators, demonstrated that large-scale precipitation projections lie within the uncertainty envelope of high resolution IPCC-class models, which have themselves been validated against proxy data in the Mid-Holocene ${ }^{78}$, the Last Glacial Maximum ${ }^{78}$ and the Pliocene ${ }^{79}$.

In this study, we have validated the simulated present-day monsoon system in our precise model setup in Supplementary Fig. 11, which compares global fields of precipitation (2005-2015) with NCEP reanalysis ${ }^{80}$, and Supplementary Fig. 12 which compares the zonally averaged $\left(70^{\circ} \mathrm{E}-90^{\circ} \mathrm{E}\right)$ distribution of modern simulated rainfall (2005-2015) through the seasonal cycle with both observations and high-resolution simulations ${ }^{81}$. Zonally averaged rainfall in PLASIM-GENIE peaks at $14 \mathrm{~mm} /$ day, slightly later (August) and at slightly lower latitudes $\left(15^{\circ} \mathrm{N}\right)$ than observations, but generally falling within the range of high-resolution model behaviour. We note that the emulator calculates annual average rainfall over large spatial scales (Fig. 3) and therefore does not rely on the details of this spatiotemporal distribution.

PLASIM-GENIE parametric uncertainty. Model uncertainty is not captured by the emulator, because it was built from simulations with a single parameter set. In order to validate the robustness of the results under model uncertainty, we performed a series of perturbed parameter ensembles using a 69 -member pre-calibrated parameter $\operatorname{set}^{73}$. These ensembles considered the forcings of orogeny (scaling by $50 \%$ ), $\mathrm{CO}_{2}$ (doubling to $560 \mathrm{ppm}$ ), precession (reversed phase) and LGM ice sheets and are summarised in Supplementary Fig. 13. Under parametric uncertainty, the three dominant drivers of uncertainty (Table 1), namely orogeny, $\mathrm{CO}_{2}$ and precession, all drive ISM change that is significant with respect to the baseline preindustrial state and, despite significant uncertainty, all drive change of consistent sign. In all simulations, both doubled $\mathrm{CO}_{2}$ and precession-reversal drive a strengthening of the monsoon while reduced orogeny drives a weakening. The optimised parameter set used to build the emulator lies close to the centre of all three ensembles. In contrast, the modest role of ice sheets (Table 1) is not robust under parametric uncertainty and should be treated with caution. Simulated SEAM rainfall is dominated by orogeny in all ensemble members. SEAM changes driven by $\mathrm{CO}_{2}$ and precession are modest and (in contrast to the ISM) of uncertain sign, indicating that the phasing of orbitally-driven SEAM change should be treated with caution. We note that precession was found to be the dominant driver of Eocene monsoon variability simulated by PLASIM-GENIE in a fully altered paleogeography ${ }^{82}$. Reduced SEAM rainfall in response to LGM ice sheet is robust under parametric uncertainty.

Boundary condition uncertainties. Further uncertainties arise from the forcing boundary conditions. A similar simulation to our globally-scaled $30 \mathrm{Ma}$ orogeny was performed in $\operatorname{HadCM} 3^{83}$, where global orogeny was reduced to $45 \%$ of modern relative to a world with a $1000 \mathrm{~m}$ Tibetan plateau but otherwise flat. Runoff from the Yangzte and Pearl rivers, which have catchment areas in the north of our modelled SEAM region, was found to reduce to approximately half of that under present-day orogeny, consistent with the rainfall reductions seen in the emulator (Fig. 3b) and the sensitivity simulation (Supplementary Figs. 2a and 17a). However, it is informative to examine the sensitivity with respect to the spatial distribution of the modelled orogeny. Supplementary Fig. 14 compares the distribution of northern summer rainfall in the baseline preindustrial simulation with simulations that flatten either the northern Tibetan Plateau or the southern Tibetan plateau, which includes the Himalayas. Flattening the northern plateau has a modest effects on both systems, while flattening the southern plateau and Himalayas substantially reduces SEAM rainfall. This is consistent with earlier work ${ }^{84}$ which showed that the large-scale South Asian summer monsoon circulation is largely unaffected by removal of the Tibet plateau as long as the Himalayas are preserved. A closely related experiment ${ }^{85}$, but at very high resolution $\left(0.23^{\circ} \times 0.31^{\circ}\right)$, similarly concluded that the Himalayas are sufficient to sustain the Indian and Asian monsoon. Highresolution models are essential for detailed monsoon projections. For instance, $0.5^{\circ}$ resolution has been found to be needed ${ }^{86}$ to capture critical elements of the local monsoon moisture transport, a resolution which exceeds that of most state-of theart models. However, these comparisons suggest that large-scale monsoon features can be simulated at lower resolution, and furthermore that our emulators are unlikely to be sensitive to the details of the historic uplift. We note that simulations ${ }^{87}$ in a $40 \mathrm{Ma}$ paleogeography (pre-dating the assumed range of validity of our emulator), implied substantially altered atmospheric circulation patterns 
from modern conditions, driving aridity over northern India and the HTP. While we capture elements of this in our scaled orography experiments (Supplementary Figs. 2a and 17a), the drying in PLASIM-GENIE is less pronounced and located further east. These differences may, at least in part, reflect the different orography assumptions.

A second important boundary condition uncertainty is the depth of Panama strait, which we have assumed to be $\sim 1000 \mathrm{~m}$. We performed a simulation with an $80 \mathrm{~m}$ deep straight, illustrated in Supplementary Fig. 15. In this simulation, freshening of the Atlantic does not penetrate to high northern latitudes and does not drive a weakening of the Atlantic meridional overturning circulation, nor of the Asian monsoon (in fact they both show increased strength, associated with increased surface Atlantic salinity at high latitudes). This illustrates, perhaps unsurprisingly, that the emulated step-change in ISM rainfall associated with Panama closure (Fig. 3 ) is a highly simplified representation of the transition.

In Supplementary Fig. 16, we consider a $3.5 \mathrm{Wm}^{-2}$ reduction in the solar constant under $30 \mathrm{Ma}$ boundary conditions, an effect which was neglected in the emulators. Simulated annual SEAM rainfall is unchanged, ISM annual rainfall is reduced by $28 \mathrm{~mm}$, and there are changes in the seasonal distributions of both systems. However, these changes are modest (implied $\sqrt{ }$ total effect $\sim 10 \mathrm{~mm}$ ) compared to the other drivers (Table 1).

A further source of boundary condition uncertainty, distinct from the implementation choices, are the uncertain timings and magnitudes of the forcings. We present emulator sensitivities in Supplementary Figs. 18, 19 and 20, which test the effects of Panama closure timing (7-3 Ma), Tethys closure timing (17-13 Ma), atmospheric $\mathrm{CO}_{2}$ (reduced to $560 \mathrm{ppm}$ at the MMCO, see Supplementary Fig. 18) and changed orogeny timing (see Supplementary Fig. 18). The low-start linear orogeny approximates the growth of the Himalayas ${ }^{88}$, included because of the sensitivity of the simulated Asian monsoon circulation to the Himalayan orogeny ${ }^{69}$. These emulations do not show any unexpected behaviour, but serve to demonstrate the range of sensitivity to uncertain timing assumptions.

\section{Data availability}

All relevant data are available from the authors. Source data are provided with this paper.

\section{Code availability}

The PLASIM-GENIE model is open access software, implemented in 'cgenie.muffin', which can be found at https://github.com/derpycode/cgenie.muffin. The emulations were performed in R. The R code and input data are provided in the appendix appendix.tar.gz.

Received: 26 June 2020; Accepted: 26 May 2021;

Published online: 29 June 2021

\section{References}

1. An, Z. et al. Global monsoon dynamics and climate change. Annu. Rev. Earth Planet. Sci. 43, 29-77, https://doi.org/10.1146/annurev-earth-060313-054623 (2015).

2. Farnsworth, A. et al. Past East Asian monsoon evolution controlled by paleogeography, not CO2. Sci. Adv. 2019, 5 (2019).

3. Mohtadi, M., Prange, M. \& Steinke, S. Palaeoclimatic insights into forcing and response of monsoon rainfall. Nature 533, 191-199, https://doi.org/10.1038/ nature17450 (2016).

4. Holden, P. B. et al. PLASIM-GENIE v1.0: a new intermediate complexity AOGCM. Geosci. Model Dev. 9, 3347-3361, https://doi.org/10.5194/gmd-93347-2016 (2016).

5. Clemens, S. C., Prell, W. L. \& Sun, Y. Orbital-scale timing and mechanisms driving Late Pleistocene Indo-Asian summer monsoons: reinterpreting cave speleothem $818 \mathrm{O}$. Paleoceanography 25, PA4207 (2010).

6. Clemens, S. C. \& Prell, W. L. A 350,000 year summer-monsoon multi-proxy stack from the Owen Ridge, Northern Arabian Sea. Mar. Geol. 201, 35-51 (2003).

7. Gebregiorgis, D. et al. Southern Hemisphere forcing of South Asian monsoon precipitation over the past $\sim 1$ million years. Nat. Commun. 9, 4702 (2018).

8. Maher, B. A. \& Thompson, R. Oxygen isotopes from Chinese caves: records not of monsoon rainfall but of circulation regime. J. Quat. Sci. 27, 615-624 (2012).

9. Nilsson-Kerr, K. et al. Role of Asian summer monsoon subsystems in the inter-hemispheric progression of deglaciation. Nat. Geosci. 12, 290 (2019).

10. Saltelli A., Chan K. \& Scott M. Sensitivity analysis (Wiley, New York, Roustant, 2008).

11. Ramstein, G., Fluteau, F., Besse, J. \& Joussaume, S. Effect of orogeny, plate motion and land-sea distribution on Eurasian climate change over the past 30 million years. Nature 386, 788-795, https://doi.org/10.1038/386788a0 (1997).

12. Fluteau, F., Ramstein, G. \& Besse, J. Simulating the evolution of the Asian and African monsoons during the past $30 \mathrm{Myr}$ using an atmospheric general circulation model. J. Geophys. Res. Atmospheres 104, 11995-12018, https://doi. org/10.1029/1999JD900048 (1999).

13. Zhang, Z., Wang, H., Guo, Z. \& Jiang, D. What triggers the transition of palaeoenvironmental patterns in China, the Tibetan Plateau uplift or the Paratethys Sea retreat? Palaeogeogr. Palaeoclimatol. Palaeoecol. 245, 317-331, https://doi.org/10.1016/j.palaeo.2006.08.003 (2007).

14. Kaya, M. Y. et al. Paleogene evolution and demise of the proto-Paratethys Sea in Central Asia (Tarim and Tajik basins): role of intensified tectonic activity at ca. 41 Ma. Basin Res. 31, 461-486, https://doi.org/10.1111/bre.12330 (2019).

15. Armstrong, H. A. \& Allen, M. B. Shifts in the intertropical convergence zone, Himalayan exhumation, and late Cenozoic climate. Geology 39, 11-14, https://doi.org/10.1130/G31005.1 (2011).

16. Sun, Y. et al. Astronomical and glacial forcing of East Asian summer monsoon variability. Quat. Sci. Rev. 115, 132-142, https://doi.org/10.1016/j. quascirev.2015.03.009 (2015).

17. Clemens, C. et al. Precession-band variance missing from East Asian monsoon runoff. Nat. Commun. 9, 3364 (2018).

18. Cai, Y. et al. Variability of stalagmite-inferred Indian monsoon precipitation over the past 252, 000 y. Proc. Natl Acad. Sci. USA 112, 2954-2959 (2015).

19. Lau, K. M., Kim, K. M. \& Yang, S. Dynamical and boundary forcing characteristics of regional components of the Asian summer monsoon. J. Clim. 13, 2461-2482 (2000). https://doi.org/10.1175/1520-0442(2000)013<2461: $\mathrm{DABFCO}>2.0 . \mathrm{CO} ; 2$.

20. Wang, P. et al. Evolution and variability of the Asian monsoon system: state of the art and outstanding issues. Quat. Sci. Rev. 24, 595-629, https://doi.org/ 10.1016/j.quascirev.2004.10.002 (2005).

21. Liu, X. D. \& Yin, Z. Y. Sensitivity of East Asian monsoon climate to the uplift of the Tibetan Plateau. Palaeogeogr. Palaeoclimatol. Palaeoecol. 183, 223-245 (2002).

22. Broccoli, A. J., Dahl, K. A. \& Stouffer, R. J. Response of the ITCZ to Northern Hemisphere cooling. Geophys. Res. Lett. 33, 1-4, https://doi.org/10.1029/ 2005GL024546 (2006).

23. Yang, S., Galbraith, E. \& Palter, J. Coupled climate impacts of the Drake Passage and the Panama Seaway. Clim. Dyn. 43, 37-52, https://doi.org/ 10.1007/s00382-013-1809-6 (2014).

24. Haug, G. H., Tiedemann, R., Zahn, R., \& Ravelo, A. C. Role of Panama uplift on oceanic freshwater balance. Geology 29, 207-210. https://doi.org/10.1130/ 0091-7613(2001)029<0207:ROPUOO >2.0.CO;2 (2001).

25. Zhang, X. et al. Changes in equatorial Pacific thermocline depth in response to Panamanian seaway closure: Insights from a multi-model study. Earth Planet. Sci. Lett. 317-318, 76-84, https://doi.org/10.1016/j.epsl.2011.11.028 (2012).

26. Hansen, J. et al. Climate impact of increasing atmospheric carbon dioxide Science 213, 957-966, https://doi.org/10.1126/science.213.4511.957 (1981).

27. Hamon, N., Sepulchre, P., Lefebvre, V. \& Ramstein, G. The role of eastern Tethys seaway closure in the Middle Miocene Climatic Transition (ca. $14 \mathrm{Ma}$ ). Clim. Past 9, 2687-2702 (2013). www.clim-past.net/9/2687/2013/10.5194/cp9-2687-2013.

28. Rowley, D. B. \& Currie, B. S. Palaeo-altimetry of the late Eocene to Miocene Lunpola basin, central Tibet. Nature 439, 677-681 (2006a).

29. Bartoli, G., Hönisch, B. \& Zeebe, R. E. Atmospheric CO2 decline during the Pliocene intensification of Northern Hemisphere glaciations. Paleoceanography 26, 1-14, https://doi.org/10.1029/2010PA002055 (2011).

30. Heitmann et al. Orbitally-paced variations of water availability in the SE Asian Monsoon region following the Miocene Climate Transition. Earth Planet. Sci. Lett. 474, 272-282, https://doi.org/10.1016/j.epsl.2017.06.006 (2017).

31. Schneider, B. \& Schmittner, A. Simulating the impact of the Panamanian seaway closure on ocean circulation, marine productivity and nutrient cycling. Earth Planet. Sci. Lett. 246, 367-380, https://doi.org/10.1016/j. epsl.2006.04.028 (2006)

32. Frierson, D. M. W. et al. Contribution of ocean overturning circulation to tropical rainfall peak in the Northern Hemisphere. Nat. Geosci. 6, 940-944, https://doi.org/10.1038/NGEO1987 (2013).

33. Marshall, J., Donohoe, A., Ferreira, D. \& McGee, D. The ocean's role in setting the mean postion of the Inter-Tropical Covergence Zone. Clim. Dyn. 42, 1967-1979, https://doi.org/10.1007/s00382-013-1767-z (2014).

34. Tada, R., Zheng, H. \& Clift, P. D. Evolution and variability of the Asian monsoon and its potential linkage with uplift of the Himalaya and Tibetan Plateau. Prog. Earth Planet. Sci. 3, 4, https://doi.org/10.1186/s40645-016-0080-y (2016).

35. Molnar, P., Boos, W. R. \& Battisti, D. S. Orographic controls on climate and paleoclimate of asia: thermal and mechanical roles for the Tibetan Plateau. Annu. Rev. Earth Planet. Sci. 38, 77-102, https://doi.org/10.1146/annurevearth-040809-152456 (2010).

36. Clift, P. D., Wan, S. \& Blusztajn, J. Reconstructing chemical weathering, physical erosion and monsoon intensity since $25 \mathrm{Ma}$ in the northern South China Sea: a review of competing proxies. Earth Sci. Rev. 130, 86-102, https://doi.org/10.1016/j.earscirev.2014.01.002 (2014).

37. Huang, C. \& Hinnov, L. Astronomically forced climate evolution in a saline lake record of the middle Eocene to Oligocene, Jianghan Basin, China. Earth 
Planet. Sci. Lett. 528, 115846, https://doi.org/10.1016/j.epsl.2019.115846 (2019).

38. Meijer, N. et al. Central Asian moisture modulated by proto- Paratethys Sea incursions since the early Eocene. Earth Planet. Sci. Lett. 510, 73-84, https://doi.org/10.1016/j.epsl.2018.12.031 (2019).

39. Ao, H. et al. Orbital climate variability on the northeastern Tibetan Plateau across the Eocene-Oligocene transition. Nat. Commun. 11, https://doi.org/ 10.1038/s41467-020-18824-8 (2020).

40. Nilsson-Kerr, K. et al. Dipole patterns in tropical precipitation were pervasive across landmasses through Marine Isotope Stage 5. Communications Earth \& Environment 264 (2021)

41. He, H., Sun, J., Li, Q. \& Zhu, R. New age determination of the Cenozoic Lunpola basin, central Tibet. Geol. Mag. 149, 141-145, https://doi.org/ 10.1017/S0016756811000896 (2012).

42. Wang, E., et al. Two-phase growth of high topography in eastern Tibet during the Cenozoic. Nat. Geosci. https://doi.org/10.1038/NGEO1538 (2012).

43. Harris, N. The elevation history of the Tibetan Plateau and its implications for the Asian monsoon. Palaeogeogr., Palaeoclimatol., Palaeoecol. 241, 4-15, https://doi.org/10.1016/j.palaeo.2006.07.009 (2006).

44. Wang, B., Kaakinen, Anu \& Clift, PeterD. Tectonic controls of the onset of aeolian deposits in Chinese Loess Plateau-a preliminary hypothesis. Int. Geol. Rev. 60, 945-955, https://doi.org/10.1080/00206814.2017.1362362 (2017).

45. Huber, M. \& Goldner, A. Eocene monsoons. J. Asian Earth Sci. 44, 3-23, https://doi.org/10.1016/j.jseaes.2011.09.014 (2012).

46. Botsyun, S. et al. Revised paleoaltimetry data show low Tibetan Plateau elevation during the Eocene. Science 363, eaaq1436, https://doi.org/10.1126/ science.aaq1436 (2019)

47. Luethi, D. et al. High-resolution carbon dioxide concentration record 650,000-800,000 years before present. Nature 453, 379-382, https://doi.org/ 10.1038/nature06949 (2008).

48. Stap, L. B., van de Wal, R. S. W., de Boer, B., Bintanja, R. \& Lourens, L. J. The influence of ice sheets on temperature during the past 38 million years inferred from a one-dimensional ice sheet-climate model. Clim 13, 1243-1257, https://doi.org/10.5194/cp-13-1243-2017 (2017).

49. Zhang, Y. G., Pagani, M., Liu, Z., Bohaty, S. M. \& DeConto, R. A 40-millionyear history of atmospheric CO2. Philos. Trans. R. Soc. A 371, 20130096, https://doi.org/10.1098/rsta.2013.0096 (2013).

50. Krapp, M. Middle Miocene Climate Evolution: The Role of Large-Scale Ocean Circulation and Ocean Gateways. Reports on Earth System Science, 111, ISSN 1614-1199, Max-Planck-Institut für Meteorologie, Hamburg, (2012).

51. Goldner, A., Herold, N. \& Huber, M. The challenge of simulating the warmth of the mid-Miocene climatic optimum in CESM1. Clim. Past 10, 523-536, www.clim-past.net/10/523/2014/10.5194/cp-10-523-2014 (2014).

52. Holbourn, A. E. et al. Late Miocene climate cooling and intensification of southeast Asian winter monsoon. Nat. Commun. 9, 1584, https://doi.org/ 10.1038/s41467-018-03950-1 (2018).

53. Badger, M. P. S. et al. Insensitivity of alkenone carbon isotopes to atmospheric CO2 at low to moderate CO2 levels. Clim. Past 15, 539-554, https://doi.org/ 10.5194/cp-15-539-2019 (2019).

54. Kasbohm, J. \& Schoene B. Rapid eruption of the Columbia River flood basalt and correlation with the mid-Miocene climate optimum, Sci. Adv. 4, eaat8223 (2018).

55. Kominz, M. A. Sea level variations over geologic time, in Encyclopaedia of Ocean Sciences (Academic Press, 2001) https://doi.org/10.1006/ rwos.2001.0255.

56. Laskar, J. et al. A long term numerical solution for the insolation quantities of the Earth. Astron. Astrophys. 428, 261-285, https://doi.org/10.1051/00046361:20041335 (2004).

57. Williamson, M. S., Lenton, T. M., Shepherd, J. G. \& Edwards, N. R. An efficient numerical terrestrial scheme (ENTS) for Earth system modelling. Ecol. Model. 198, 362-374, https://doi.org/10.1016/j.ecolmodel.2006.05.027 (2006).

58. Bosboom, R. et al. Timing, cause and impact of the late Eocene stepwise sea retreat from the Tarim Basin (west China). Palaeogeogr. Palaeoclimatol. Palaeoecol. 403, 101-118, https://doi.org/10.1016/j.palaeo.2014.03.035 (2014)

59. Hill, D. J. et al. Paleogeographic controls on the onset of the Antarctic circumpolar current. Geophys. Res. Lett. 40, 5199-5204, https://doi.org/ 10.1002/grl.50941 (2013).

60. Ellis, D. \& Stoker, M. S. The Faroe-Shetland Basin: a regional perspective from the Palaeocene to the present day and its relationship to the opening of the North Atlantic Ocean, February 20, 2014 (Geological Society, London, Special Publications, 2014), https://doi.org/10.1144/SP397.1.

61. O'Dea, A., et al. Formation of the Isthmus of Panama. Sci. Adv. 2, e1600883 (2016).

62. Molnar, P. Closing of the Central American Seaway and the Ice Age: a critical review. Paleoceanography 23, PA2201, https://doi.org/10.1029/2007PA00157 (2008).
63. Molnar, P. Comment (2) on "Formation of the isthmus of Panama" by O'Dea et al. Sci. Adv. 3, e1602320 (2017)

64. Montes, C. et al. Middle Miocene closure of the Central American Seaway. Science 348, 226-229 (2015)

65. Jakobsson, M. et al. The early Miocene onset of a ventilated circulation regime in the Arctic Ocean. Nature 447, 968-990, https://doi.org/10.1038/ nature05924 (2007).

66. Vasiliev, I. et al. How dry was the Mediterranean during the Messinian salinity crisis? Palaeogeogr. Palaeoclimatol. Palaeoecol. 471, 120-133, https://doi.org/ 10.1016/j.palaeo.2017.01.032 (2017).

67. Gladenkov, A. Y., Oleinik, A. E., Marincovich, L. Jr. \& Barinov, K. B. A refined age for the earliest opening of Bering Strait. Paleogeog. Paleoclim. Paleoeco. 183, 321-328 (2002).

68. Kuhnt, W., Holbourn, A., Hall, R., Zuvela, M., \& Kase, R. Neogene history of the Indonesian throughflow. Am. Geophys. Union https://doi.org/10.1029/ 149GM16 (2004).

69. Cane, M. A. \& Molnar, P. Closing of the Indonesian seaway as a precursor to East African aridification round 3-4 million years ago. Nature 41, 157-162 (2001).

70. Tillinger, D. \& Gordon, A. L. Fifty years of the Indonesian throughflow. J. Clim. 22, 6342-6355, https://doi.org/10.1175/2009JCLI2981 (2009).

71. Fedorov, A. V. et al. The Pliocene Paradox (Mechanisms for a Permanent El Niño). Science 312, 1485-1489 (2006).

72. Holden, P. B. et al. PALEO-PGEMv1.0: a statistical emulator of PliocenePleistocene climate. Geosci. Model Dev. 12, 5137-5155, https://doi.org/ 10.5194/gmd-12-5137-2019 (2019)

73. Holden, P. B. et al. Climate-carbon cycles uncertainties and the Paris Agreement. Nat. Clim. Change 8, 609-613 (2018).

74. Peltier, W. Global isostasy and the surface of the ice-age Earth: The ICE-5G (VM2) model and GRACE. Annu. Rev. Earth Planet. Sci. 32, 111-149, https:// doi.org/10.1146/annurev.earth.32.082503.144359 (2004).

75. Araya-Melo, P. A., Crucifix, M. \& Bounceur N. Global sensitivity analysis of the Indian monsoon during the Pleistocene. Clim. Past 11, 45-61, https://doi. org/10.5194/cp-11-45-2015 (2015).

76. Rasmussen, C. E. Gaussian processes in machine learning, in Advanced Lectures on Machine Learning, (eds Bousquet, O., von Luxburg, U. \& Rätsch, G.) (Springer, Berlin, Heidelberg, New York, 2004).

77. Roustant, O., Ginsbourger, D. \& Deville, Y. DiceKriging, DiceOptim: two R packages for the analysis of computer experiments by kriging-based metamodeling and optimization. J. Stat. Softw. 2012, 1-55 http://www. jstatsoft.org (2012).

78. Braconnot, P. et al. Results of PMIP2 coupled simulations of the MidHolocene and Last Glacial Maximum-Part 1: experiments and large-scale features. Clim 3, 261-277 (2007).

79. Haywood, A. M. et al. Large-scale features of Pliocene climate: results from the Pliocene Model Intercomparison Project. Clim 9, 191-209, https://doi.org/ 10.5194/cp-9-191-2013 (2013).

80. Kalnay, E. et al. The NCEP/NCAR 40-Year reanalysis project. B. Am. Meteorol. Soc. 77, 437-471 (1996).

81. Sperber, K. R. et al. The Asian summer monsoon: an intercomparison of CMIP5 vs. CMIP3 simulations of the late 20th century. Clim. Dyn. 41, 2711-2744 (2013).

82. Keery, J. S., Holden, P. B. \& Edwards, N. R. Sensitivity of the Eocene climate to CO2 and orbital variability. Clim. Past 14, 215-238 (2018).

83. Lunt, D. J., Flecker, R. \& Clift, P. D. The impacts of Tibetan uplift on paleoclimate proxies, In Monsoon Evolution and Tectonics-Climate Linkage in Asia (eds Clift, P. D., Tada, R. \& Zheng, H.) 342, 279-291 (Geological Society, London, Special Publications, 2010).

84. Boos, W. R. \& Kuang, Z. Dominant control of the South Asian monsoon by orographic insulation versus plateau heating. Nature 463, 218-223 (2010).

85. Acosta, R. P. \& Huber, M. Competing topographic mechanisms for the Summer Indo-Asian Monsoon. Geophys. Res. Lett. 47, e2019GL085112 (2020).

86. Acosta, R. P. \& Huber, M. The neglected Indo-Gangetic Plains low-level jet and its importance for moisture transport and precipitation during the peak summer monsoon. Geophys. Res. Lett. 44, 8601-8610 (2017).

87. Tardif, D. et al. The origin of Asian monsoons: a modelling perspective. Climate 16, 847-865 (2020).

88. Spicer, R. A. et al. Why 'the uplift of the Tibetan Plateau' is a myth? Natl Sci. Rev. nwaa091, https://doi.org/10.1093/nsr/nwaa091 (2020).

\section{Acknowledgements}

P.H. and N.R.E. acknowledge NERC funding (grant number NE/P015093/1). P.A. acknowledges NERC and UKIODP funding (NE/M021181/1). We thank Clare Warren and Robert Spicer for careful reading of the manuscript. 


\section{Author contributions}

P.A. and P.B.H. conceived and designed the experiment. P.B.H. performed the PLASIMGENIE simulations. J.R.T. developed the emulators and performed all of the emulation analysis with guidance from P.B.H. and N.R.E.. C.A.P. developed the boundary condition data and early versions of the emulation approach. Scientific expertise was provided by N.B.W.H. (Himalayan and Tibetan tectonics and Asian monsoon), P.A. (Asian Monsoon dynamics), P.B.H. (Earth system modelling and emulation) and N.R.E. (Earth system dynamics). J.R.T. wrote the manuscript with contributions from all authors.

\section{Competing interests}

The authors declare no competing interests.

\section{Additional information}

Supplementary information The online version contains supplementary material available at https://doi.org/10.1038/s41467-021-24244-z.

Correspondence and requests for materials should be addressed to P.B.H.

Peer review information Nature Communications thanks Alexander Farnsworth, Delphine Tardif and the other, anonymous, reviewer(s) for their contribution to the peer review of this work. Peer reviewer reports are available.
Reprints and permission information is available at http://www.nature.com/reprints

Publisher's note Springer Nature remains neutral with regard to jurisdictional claims in published maps and institutional affiliations.

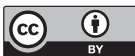

Open Access This article is licensed under a Creative Common Attribution 4.0 International License, which permits use, sharing, adaptation, distribution and reproduction in any medium or format, as long as you give appropriate credit to the original author(s) and the source, provide a link to the Creative Commons license, and indicate if changes were made. The images or other third party material in this article are included in the article's Creative Commons license, unless indicated otherwise in a credit line to the material. If material is not included in the article's Creative Commons license and your intended use is not permitted by statutory regulation or exceeds the permitted use, you will need to obtain permission directly from the copyright holder. To view a copy of this license, visit http://creativecommons.org/ licenses/by/4.0/.

(C) The Author(s) 2021 